\title{
Erratum to: Hepatic Encephalopathy
}

Mark A. Ellul and Tim Cross

\section{Erratum to:}

Chapter 4 (page 63) in: T. Cross (ed.), Liver Disease in Clinical Practice, In Clinical Practice, DOI 10.1007/978-3-319-43126-0_4

The image and the legend of Figure 4.1 in Chapter 4 is incorrect.

The correct figure and legend is placed in next page (E2):

The updated original online version for this chapter can be found at DOI 10.1007/978-3-319-43126-0_4 


\section{E2 Erratum}

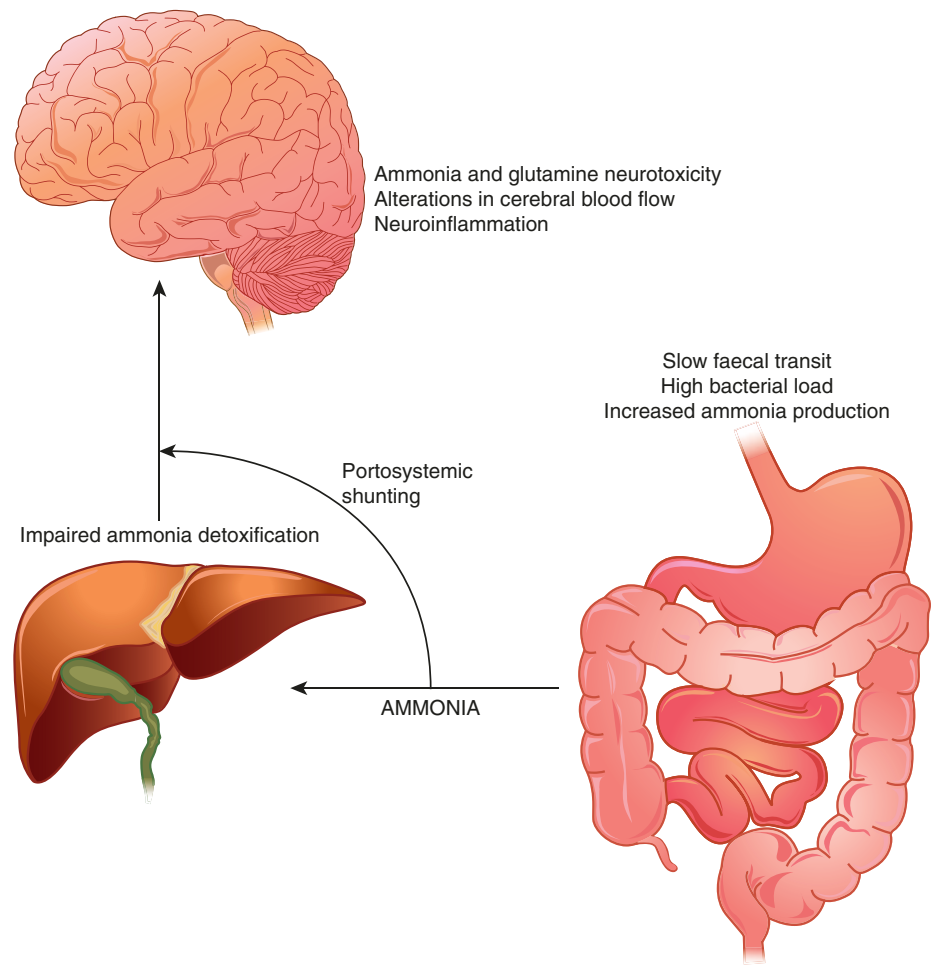

FIgURE 4.I Outline of the proposed pathogenesis of hepatic encephalopathy 